\title{
Clinical Trial Design, Endpoints and Regulatory Considerations in Heart Failure
}

\section{Giuseppe MC Rosano}

Centre for Clinical \& Basic Research IRCCS San Raffaele Pisana, via della Pisana, 235, 00163 Rome, Italy

\section{Corresponding author:}

Professor Giuseppe M.C. Rosano,

Centre for Clinical \& Basic Research IRCCS San Raffaele Pisana,

via della Pisana, 235, 00163 Rome, Italy

Email: giuseppe.rosano@gmail.com

\begin{abstract}
After the withdrawal of flosequinan in the early 1990's, because of an increased risk of mortality and fatal arrhythmias, the bar for the approval of new drugs in heart failure has been raised and regulatory agencies have requested evidence for the efficacy of new treatments on mortality and morbidity end-points. However, more recently, regulatory agencies have become more open to include the assessment of functional capacity as an efficacy endpoint, at least in selected subgroups of patients. Therefore, a new therapy for the treatment of heart failure can be approved if it improves survival and/or reduces hospitalisations or if it safely improves functional capacity. This article reviews clinical trial design, trial endpoints and regulatory issues in Heart Failure trials.
\end{abstract}

Keywords: Heart failure; end-points; regulatory approval; clinical trial design

Citation: $\quad$ Rosano GMC. Clinical Trial Design, Endpoints and Regulatory Considerations in Heart Failure. International Cardiovascular Forum Journal. 2019;17:19-21. DOI: 10.17987/icfj.v17i0.595

\section{Introduction}

After the withdrawal of flosequinan in the early 1990's, because of an increased risk of mortality and fatal arrhythmias, the bar for the approval of new drugs in heart failure has been raised and regulatory agencies have requested evidence for the efficacy of new treatments on mortality and morbidity end-points. However, more recently, regulatory agencies have become more open to include the assessment of functional capacity as an efficacy endpoint, at least in selected subgroups of patients. Therefore, a new therapy for the treatment of heart failure can be approved if it improves survival and/or reduces hospitalisations or if it safely improves functional capacity.

Therefore, in order to justify regulatory approval, the clinical development programme of new agent must demonstrate clinically relevant improvement in a meaningful clinical end point. Composite end points can be devised to improve trial efficiency and adequate assessment of efficacy of newer therapeutic agents provided that they are associated with a good safety profile.[1-3]

Furthermore, apart from heart failure with reduced ejection fraction (HFrEF) newer entities such as heart failure with a normal or relatively preserved ejection fraction (HFpEF, HFmrEF), for which no treatment is currently available, have been recognised. [4] The distinction between patients with HFrEF from those with HFpEF and HFmrHF is important because differentiating between groups with different underlying pathophysiological, haemodynamic, and neurohormonal abnormalities may help explain differing clinical features, different outcomes and most importantly differing responses to therapy.[4]

Patients with heart failure may fluctuate between periods of stability and periods of de-compensation leading to hospitalisations [termed hospitalized heart failure (HFH)].[5-7] With the exception of early trials in ACE inhibitors and to a lesser extent angiotensin receptor blockers in the related area of post-MI heart failure, heart failure therapies approved for patients with chronic heart failure have not been tested in patients recently discharged after an episode of de-compensation. The mortality at 3 months of patients discharged after an acute episode of heart failure is approximately $10-15 \%$ and reaches $20-35 \%$ at 1 year. Clinical trials for the development of new therapeutic agents have traditionally included either patients in the acute phase who had just been hospitalized (within few days or hours) or patients that have been stable for few months. Patients who are still hospitalised but are not receiving intra-venous therapies and those who are in the immediate postdischarge phase have classically been excluded from heart failure clinical trials.

HFH is often used as a co-primary or part of a composite primary endpoint in heart failure trials. Despite its clinical relevance, its use as an endpoint in heart failure trials is controversial since the threshold for hospitalization, local standards of care and length of hospitalisation may differ across different regions. Therefore, 
there is a need for a better definition of $\mathrm{HFH}$ in order to harmonise its adjudication. Furthermore, some patients with heart failure are repeatedly hospitalized because of repetitive episodes of decompensation and yet such repeated events are often ignored and "time to first event" analyses are used instead. Repeated event analyses may increase statistical power, leading to smaller sample sizes and better quantification of morbid events.

Another important point in clinical trial design in heart failure is the identification of surrogate end points that may predict significant clinical benefits. Indeed, despite phase II clinical trials suggesting efficacy of new compounds on surrogate end points, most agents have either failed to demonstrate efficacy or have even been proven negative on long-term outcomes. [8-9] Therefore, there is still the need to identify end points that may represent an adequate prognostic surrogate. Similarly biomarkers have not been shown to predict the clinical efficacy of drug therapies in heart failure.

\section{Efficacy criteria for developing agents for the treatment of chronic heart failure}

The primary aim of new treatments for chronic heart failure is to improve prognosis (survival and/or hospitalisations). Functional capacity is also an important end point to assess in patients with heart failure. However, the approval of new agents based on functional capacity has been made difficult by the problems encountered in the past with some treatments that were effective in improving exercise capacity, but that also had a negative effect on survival.

Efficacy end-points must be clinically relevant, and can be usefully classified into three groups. Group 1: all cause mortality, cardiovascular mortality, hospitalisation for heart failure and recurrent morbid events $(\mathrm{HFH}$, worsening heart failure without hospitalisation, hospitalisation for cardiac causes, cardiovascular mortality). Group 2: functional capacity. Group 3: haemodynamic changes (eg LVEF, left ventricular remodeling), biomarkers, symptoms, quality of life

Group 1 endpoints are by and large approvable; group 2 potentially so, but given the negative experiences of the past, positive effects on functional capacity must be supported by neutral or, preferably, favourable effects on mortality and morbidity; but group 3 end-points are proof of concept only, as they do not in themselves confer patient benefit.

\section{Primary end points}

Primary end points should include all cause mortality, hospitalisation for heart failure and/or the clinical composite end point of cardiovascular mortality, hospitalisation for heart failure, worsening heart failure without hospitalisation, or hospitalisation for cardiac causes. Pre-specified composite end points may be acceptable but must include mortality and hospitalisation for heart failure and, ideally, for cardiovascular causes. Composite end-points including repeated hospitalizations can be used as primary composite end-points.

The effect of a new pharmacological agent for the treatment of heart failure on mortality can only be assessed with a randomized placebo or active treatment-controlled trial. Survival studies using positive control drug(s) may be acceptable but the comparator agent should be limited to drugs that have consistently shown efficacy on survival.

Although overall mortality should be the preferred mortality end point in chronic heart failure studies, both total death and causespecific death must be assessed and reported. Cardiovascular death may represent an adequate end point provided that the therapeutic effect on overall mortality is at least neutral. An excess in non-cardiovascular mortality could be acceptable, if the overall mortality is reduced or unchanged. It is important to define the mode of cardiac death and a central adjudication of the causes of death may be warranted.[11]

Hospitalisation for heart failure may be used as endpoint for efficacy. These hospitalisations should be centrally adjudicated. Hospitalisation for heart failure can be defined as those hospitalisations associated with signs and symptoms of deteriorating clinical condition along with increased plasma levels of BNP/proBNP and the need for acute treatments for heart failure (e.g., increase in diuretic dose, intravenous diuretics, or intravenous vasodilators/inotropes).

\section{Functional capacity}

Exercise capacity is a marker of clinical status and it is a more reliable end point than subjective assessment with patient related outcomes. Both maximal oxygen consumption test (MVO2, sometimes referred as peak oxygen uptake, peakVO2) and supervised 6 minute walking test (6MWT) are reliable methods for the assessment of functional capacity. Exercise testing should be performed using appropriate protocols specifically designed for the functional assessment of patients with cardiac failure.

Sub-maximal protocols should specify a priori the reasons for termination of the tests. Naïve patients to exercise protocols (bicycle, treadmill, measurement oxygen consumption) should first be made familiar with the technique before they are included in the trial. Repeated baseline and repeated follow up testing may reduce variability of the results and increase statistical power. Because of the variability in the execution and settings of the 6MWT multicentre studies must use standardised criteria and settings. The test should be supervised by a physical therapist, patients should be asked to walk on their own, and no phrases of encouragement should be offered. Patients may be allowed to stop walking if signs or symptoms of significant distress occur during the test and they should be instructed to resume walking as soon as possible.

\section{Safety}

Therapies for chronic heart failure are life-long. Therefore, the effect of new therapies on the occurrence of adverse effects and drug-to-drug interactions should always be investigated. Attention should be focused towards effects on cardiac rhythm, pro-ischaemic effects, hypotension, bradycardia, renal function and electrolyte homeostasis.

\section{Conclusions}

Newer regulatory and reimbursement practices require innovative study designs.[15] New agents for the treatment of heart failure should show a sound clinical benefit and an adequate safety profile. For these reasons all intervention studies conducted in heart failure should be reported and published.[16] 


\section{Declarations of interest}

The authors declare no conflict of interest.

\section{Acknowledgements}

The authors state that they abide by the authors' responsibilities and ethical publishing guidelines of the International Cardiovascular Forum Journal.[17]

\section{References}

1: Schüssler-Lenz M, Beuneu $C$, Menezes-Ferreira $M$, Jekerle V, Bartunek J, Chamuleau S, Celis P, Doevendans P, O’Donovan M, Hill J, Hystad M, Jovinge S, Kyselovič J, Lipnik-Stangelj M, Maciulaitis R, Prasad K, Samuel A, Tenhunen O, Tonn T, Rosano G, Zeiher A, Salmikangas P. Cell-based therapies for cardiac repair: a meeting report on scientific observations and European regulatory viewpoints. Eur J Heart Fail. 2016 Feb;18(2):133-41.

2: Anker SD, Schroeder S, Atar D, Bax JJ, Ceconi C, Cowie MR, Crisp A, Dominjon F, Ford I, Ghofrani HA, Gropper S, Hindricks G, Hlatky MA Holcomb R, Honarpour N, Jukema JW, Kim AM, Kunz M, Lefkowitz M, Le Floch C, Landmesser U, McDonagh TA, McMurray JJ, Merkely B, Packer M, Prasad K, Revkin J, Rosano GM, Somaratne R, Stough WG, Voors AA, Ruschitzka F. Traditional and new composite endpoints in heart failure clinical trials: facilitating comprehensive efficacy assessments and improving trial efficiency. Eur J Heart Fail. 2016 May;18(5):482-9.

3: Pani L, Pecorelli S, Rosano G, Anker SD, Peracino A, Fregonese L, Prasad $\mathrm{K}$, Rasi G. Steps forward in regulatory pathways for acute and chronic heart failure. Eur J Heart Fail. 2015 Jan;17(1):3-8.

4: ESC Committee for Practice Guidelines. ESC Guidelines for the diagnosis and treatment of acute and chronic heart failure 2016: The Task Force for the Diagnosis and Treatment of Acute and Chronic Heart Failure 2016 of the European Society of Cardiology. Developed in collaboration with the Heart Failure Association (HFA) of the ESC. Eur J Heart Fail. 2016 Aug;18(8):891-975.

5: Greene SJ, Shah AN, Butler J, Ambrosy AP, Anker SD, Chioncel O Collins SP Dinh W, Dunnmon PM, Fonarow GC, Lam CS, Mentz RJ, Pieske B, Roessig L, Rosano GM, Sato N, Vaduganathan M, Gheorghiade M. Designing effective drug and device development programs for hospitalized heart failure: a proposal for pretrial registries. Am Heart J. 2014 Aug;168(2):142-9.

6: Gheorghiade M, Shah AN, Vaduganathan M, Butler J, Bonow RO, Rosano GM, Taylor S, Kupfer S, Misselwitz F, Sharma A, Fonarow GC. Recognizing hospitalized heart failure as an entity and developing new therapies to improve outcomes: academics', clinicians', industry's, regulators', and payers' perspectives. Heart Fail Clin. 2013 Jul;9(3):285-90, v-vi. doi: 10.1016/j.hfc.2013.05.002.

7: Butler J, Fonarow GC, Zile MR, Lam CS, Roessig L, Schelbert EB, Shah SJ, Ahmed A, Bonow RO, Cleland JG, Cody RJ, Chioncel O, Collins SP, Dunnmon P, Filippatos G, Lefkowitz MP, Marti CN, McMurray JJ, Misselwitz F, Nodari S, O'Connor C, Pfeffer MA, Pieske B, Pitt B, Rosano G, Sabbah HN, Senni M, Solomon SD, Stockbridge N, Teerlink JR, Georgiopoulou VV, Gheorghiade M. Developing therapies for heart failure with preserved ejection fraction: current state and future directions. JACC Heart Fail. 2014 Apr;2(2):97-112.

8: Vaduganathan M, Greene SJ, Ambrosy AP, Gheorghiade M, Butler J. The disconnect between phase II and phase III trials of drugs for heart failure. Nat Rev Cardiol. 2013;10:85-97.

9: Zannad F, Garcia AA, Anker SD, Armstrong PW, Calvo G, Cleland JG, Cohn JN, Dickstein K, Domanski MJ, Ekman I, Filippatos GS, Gheorghiade M, Hernandez AF, Jaarsma T, Koglin J, Konstam M, Kupfer S, Maggioni AP, Mebazaa A, Metra M, Nowack C, Pieske B, Piña IL, Pocock SJ, Ponikowski P, Rosano G, Ruilope LM, Ruschitzka F, Severin T, Solomon S, Stein K, Stockbridge NL, Stough WG, Swedberg K, Tavazzi L, Voors AA, Wasserman SM, Woehrle H, Zalewski A, McMurray JJ. Clinical outcome endpoints in heart failure trials: a European Society of Cardiology Heart Failure Association consensus document. Eur J Heart Fail. 2013 Oct;15(10):1082-94.

10: Fishbein DP, Hellkamp AS, Mark DB et al. Use of the 6-min walk distance to identify variations in treatment benefits from implantable cardioverterdefibrillator and amiodarone: results from the SCD-HeFT (Sudden Cardiac Death in Heart Failure trial). J Am Coll Cardiol. 2014;63:2560-8

11: Seltzer JH, Turner JR, Geiger MJ, Rosano G, Mahaffey KW, White WB, Sabol MB, Stockbridge N, Sager PT. Centralized adjudication of cardiovascular endpoints in cardiovascular and noncardiovascular pharmacologic trials: a report from the Cardiac Safety Research Consortium. Am Heart J. 2015 Feb;169(2):197-204.

12: Collins SP, Pang PS, Fonarow GC, Yancy CW, Bonow RO, Gheorghiade $M$. Is hospital admission for heart failure really necessary?: the role of the emergency department and observation unit in preventing hospitalisation and rehospitalisation. J Am Coll Cardiol. 2013;61:121-6.

13: Harinstein ME, Butler J, Greene SJ, Fonarow GC, Stockbridge NL, O’Connor CM, Pfeffer MA, Mehra MR, Solomon SD, Yancy CW, Fiuzat M, Mentz RJ, Collins SP, McMurray JJ, Vaduganathan M, Dunnmon PM, Rosano GM, Dinh W, Misselwitz F, Bonow RO, Gheorghiade M. Site selection for heart failure clinical trials in the USA. Heart Fail Rev. 2015 Jul;20(4):375-83.
14: Rosano GM, Anker SD, Marrocco W, Coats AJ. Adaptive licensing - A way forward in the approval process of new therapeutic agents in Europe. Int $J$ Cardiol. 2015 Apr 1;184:568-9.

15: Pelliccia F, Rosano GM. Back to the future: the crucial role of clinical registries in the era of randomized controlled trials for identifying the optimal medical therapy of heart failure. Eur Heart $\mathrm{J}$ Cardiovasc Pharmacother. 2015 Jan; 1(1):37-8

16: Capuano A, Coats AJ, Scavone C, Rossi F, Rosano GM. Disclosure of negative trial results. A call for action. Int J Cardiol. 2015 Nov 1;198:47-8.

17. Shewan LG, Coats AJS, Henein MY. Authors' Responsibilities and Ethical Publishing. International Cardiovascular Forum Journal 2018;13:3-4, DOI: 10.17987/icfj.v13i0.525 